\title{
Acute and Long-Term Outcomes Following Pediatric Traumatic Brain Injury
}

\author{
Robyn A. Howarth ${ }^{1}$ Laura S. Blackwell ${ }^{1}$ Kim E. Ono ${ }^{1}$ \\ ${ }^{1}$ Department of Neuropsychology, Children's Healthcare of Atlanta, \\ Emory School of Medicine, Atlanta, Georgia, United States \\ J Pediatr Neuroradiol 2016;5:26-31. \\ Address for correspondence Robyn A. Howarth, PhD, Department of \\ Neuropsychology, Children's Healthcare of Atlanta, 5545 Meridian \\ Mark Road, Suite 180, Atlanta, GA 30301, United States \\ (e-mail: robyn.howarth@choa.org).
}
Abstract
Keywords
- pediatric TBI
- health-related quality of life
- outcomes

Pediatric traumatic brain injury (TBI) is one of the leading causes of death and serious disability among children and adolescents. In this review, the neuropathology and pathophysiology of pediatric TBI will be briefly discussed, including the importance of advanced neuroimaging techniques to assist with acute management and diagnostic accuracy. Then, predictors of outcome and sequelae of injury will be highlighted, across TBI severities, including impact on health-related quality of life. Finally, a case study will be presented to highlight the unique trajectory and outcome in a teenager with a severe TBI.

\section{Introduction}

Pediatric traumatic brain injury (TBI) is one of the leading causes of death and serious disability among children and adolescents. Incidence and prevalence rates of pediatric TBI are often difficult to obtain and vary by injury severity as well as mechanism of injury. In a recent report, the Centers for Disease Control and Prevention $(C D C)$ reported that children aged 0 to 4 years and adolescents aged 15 to 19 years display the highest incidence rates of TBI-related emergency department visits and/or hospitalizations. ${ }^{1}$ A majority of pediatric TBI are mild ( $\left.~ 80 \%\right)$, whereas a smaller percentage of injuries are moderate to severe., ${ }^{2,3}$

Despite physiological commonalities, the immature or developing brain likely responds differently to trauma than the mature adult brain. ${ }^{4}$ Children are more likely to experience posttraumatic edema, ischemic insult, and diffuse rather than focal injuries, which may be due to differing biomechanical properties of the developing brain. This may be related to the fact that children have a greater head-to-body ratio, less myelination, and a greater relative proportion of water content and cerebral blood volume compared with adults. ${ }^{5}$ The trajectory of recovery is known to be more variable in children compared with adults.

\section{Neuropathology and Pathophysiology of Pediatric Traumatic Brain Injury}

Depending on the mechanism of injury, pathophysiology, and regions of the brain impacted, pediatric patients will present

received

January 26, 2016 accepted

January 26, 2016 published online May 30, 2016 with a variety of primary and secondary injuries. Primary injuries are a direct result of the traumatic impact and may include skull fractures, contusions, diffuse axonal shearing, and/or vascular injury. ${ }^{6}$ Secondary injuries are insults that are triggered by the primary injury and include complications such as cerebral edema, elevated intracranial pressure, hypoxia, seizures, endocrine dysfunction, and/or autonomic instability. ${ }^{7}$ The emergence of secondary injuries can further complicate recovery, particularly following moderate to severe TBI. ${ }^{6}$

The most common causes of pediatric TBI include falls and motor vehicle accidents, which often give rise to acceleration-deceleration injuries. Acceleration-deceleration injuries may result in tearing or bruising of blood vessels that leads to focal contusions or hemorrhage. These injuries are most likely to occur in the frontal and temporal regions given their close proximity to the bony prominences of the anterior and middle fossa of the skull. ${ }^{8}$ Acceleration-deceleration injuries may also result in shearing of nerve fibers characteristic of diffuse axonal injury (DAI).

Previous studies have demonstrated that shearing lesions (hemorrhagic and nonhemorrhagic) associated with DAI occur in $\sim 40 \%$ of pediatric TBI cases. ${ }^{9}$ Subtle, microscopic injuries may also occur, which may not be seen with conventional neuroimaging modalities (e.g., computed tomography [CT] scans), yet contribute to functional lesions and suboptimal outcomes. DAI is characterized by damage to axons, commonly located in the gray-white matter junctions, the basal ganglia, periventricular white matter, corpus callosum,
Copyright $\odot 2016$ by Georg Thieme Verlag KG, Stuttgart • New York
DOI http://dx.doi.org/ 10.1055/s-0036-1584285. ISSN 1309-6680.
Injury; Guest Editors: Nadja Kadom, MD, and Max Wintermark, MD, MBA 
and parasagittal white matter, and they can affect fiber tracts of the cerebral cortex and brainstem. ${ }^{7}$

Following injury, medical professionals use various diagnostic tools to determine severity of injury. The Glasgow Coma Scale (GCS) is one of the most commonly used screening tools, which allows clinicians to assess an individual's level of consciousness and responsiveness immediately following an injury. ${ }^{10}$ Scores range from 3 to 15 . Traditionally, scores between 13 and 15 represent a mild TBI, scores between 9 and 12 represent a moderate TBI, and scores of 8 or less represent a severe TBI. Research has highlighted additional indictors of severity that should be considered, including duration of loss of consciousness (LOC), time to emerge from a minimally conscious state (MCS), length of posttraumatic amnesia, and time to follow commands ${ }^{6}$ (see - Table $\mathbf{1}$ ).

Neuroimaging plays an important role in identifying the sequelae of injury and determining the acute management of pediatric TBI. ${ }^{11}$ Recent advances in neuroimaging have helped in the clinical care and management of children and adolescents with TBI. ${ }^{12}$ Conventional imaging modalities are often used acutely following hospital admission; however, these modalities may be relatively insensitive to detecting microstructural injuries that are characteristic of DAI. More sensitive techniques, such as magnetic resonance imaging (MRI), diffusion-weighted imaging, and diffusion tensor imaging, provide high spatial resolution, which increases sensitivity for the detection of DAI. ${ }^{12}$ With advances in imaging modalities, targeted treatment and rehabilitation therapies may be administered.

Global, more diffuse, burden associated with DAI may be more important than localized injury with regard to outcomes following pediatric TBI. Over time, severe TBI may result in gradual and prolonged white matter degeneration and cortical thinning, with associated cerebral atrophy and ventricular dilation. Emerging literature focuses on identifying imaging biomarkers of tissue injury as predictors of functional outcomes. ${ }^{11,12}$ Therefore, following a moderateto-severe TBI in children and adolescents, advanced neuroimaging techniques should be considered in conjunction with conventional modalities.

\section{Predictors of Outcome}

When monitoring recovery following pediatric TBI, it is important to consider predictors of functional recovery post- injury. Various factors, including injury characteristics, noninjury-related factors, and developmental factors, have been shown to contribute to the rate and trajectory of recovery. Additionally, these factors influence one's independence with activities of daily living, or the routine activities that people actually do or can do every day without needing assistance (e.g., eating, bathing, dressing, toileting) as well as self- and parent-reported health-related quality of life (HRQL) such as children's physical, emotional, and social functioning.

\section{Injury Severity}

Injury characteristics, including severity, mechanism, and location of injury, have long been identified as predictors of morbidity and mortality in pediatric TBI. Past studies have found that severity of injury is related to several, both acute and chronic, physical, cognitive, and psychological issues. ${ }^{13}$ Neuroimaging studies in children with brain insult have shown that more diffuse or bilateral injury, regardless of age at insult, with large lesion size or extent of pathology is associated with greater impairment. ${ }^{14,15}$ Anderson and colleagues followed a large sample of children who sustained a brain injury, and found that those with severe injuries showed slower recovery rates and poorer cognitive outcomes at 5 years after injury compared with children with less severe injuries. ${ }^{16}$ The greatest deterioration of function, specifically a reduction in verbal and perceptual domains on an IQ test, was seen in the first 30 months, and then was observed to stabilize from 30 months to 5 years after injury. More severe injury has also been shown to be associated with increased utilization of school support services following injury, including special education. ${ }^{17,18}$

\section{Noninjury-Related Factors}

Premorbid psychological, behavioral, and environmental risk factors have been associated with negative outcomes and poor recovery following pediatric TBI. In an early study by Brown and colleagues, children who sustained severe TBI and had high rates of premorbid psychosocial issues were at greater risk of developing psychiatric disorders after injury. ${ }^{19}$ The presence of cognitive impairments prior to injury has also been associated with worse cognitive functioning following discharge up to 5 years postinjury. ${ }^{14,20}$ Parent ratings of preinjury behavioral issues were more strongly related to behavioral problems at 1 and 2 years after injury. ${ }^{21}$ More

Table 1 Severity classifications in traumatic brain injury

\begin{tabular}{|l|l|l|l|l|}
\hline & GCS & PTA & LOC & Initial clinical presentation \\
\hline Mild TBI & 13 to 15 & $<1 \mathrm{~d}$ & 0 to $30 \mathrm{~min}$ & $\begin{array}{l}\text { Brief change in mental status, headache, } \\
\text { dizziness, nausea/vomiting, trouble concentrating }\end{array}$ \\
\hline Moderate TBI & 9 to 12 & $>1 \mathrm{~d}$ to $<7 \mathrm{~d}$ & $>30 \mathrm{~min}$ to $<24 \mathrm{~h}$ & $\begin{array}{l}\text { Variable clinical presentation } \\
\text { Cognitive and/or physical deficits }\end{array}$ \\
\hline Severe TBI & 3 to 8 & $>7 \mathrm{~d}$ & $>24 \mathrm{~h}$ & $\begin{array}{l}\text { Coma/unresponsive wakefulness; generalized } \\
\text { responses to environment }\end{array}$ \\
\hline
\end{tabular}

Abbreviations: GCS, Glasgow Coma Scale; LOC, loss of consciousness; PTA, posttraumatic amnesia; TBI, traumatic brain injury. Source: Adapted from Management of Concussion/mTBI Working Group. ${ }^{60}$ 
proximal risk factors, including family demographics (e.g., socioeconomic status, income, parent education level), environmental factors, and quality of treatments received (e.g., acute hospitalization, rehabilitation, school-related services), have also been found to be important predictors of long-term outcomes. $^{22-25}$

\section{Developmental Factors}

Developmental factors (e.g., age at the time of injury, time since injury, age at testing) are also important. ${ }^{25-28}$ For example, children who sustain a TBI earlier in childhood, prior to 5 years of age, demonstrate more persistent deficits over time and have a slower rate of recovery than injuries sustained during late childhood or adolescence. ${ }^{25}$ Children generally show more rapid rate of recovery during the initial months and years following injury, particularly with severe versus mild injuries.

\section{Sequelae of Pediatric Traumatic Brain Injury}

Children and adolescents who sustain a TBI may experience changes in physical, cognitive, and emotional/behavioral functioning, which can increase family burden and negatively impact quality of life. ${ }^{29,30}$ As previously mentioned, several factors have been shown to influence the degree of impairment postinjury as well as the trajectory of recovery following injury, which vary depending on severity of injury. Numerous studies have also suggested that the combination of younger age at the time of injury and greater injury severity may be associated with negative outcomes over time. ${ }^{31,32}$

\section{Mild Traumatic Brain Injury}

After a mild TBI, individuals may experience a brief LOC and seek medical evaluation; however, conventional neuroimaging is unremarkable. ${ }^{6}$ Children and adolescents may experience a constellation of symptoms including somatic complaints (e.g., headaches, nausea, vomiting, sensitivity to light or sound), cognitive changes (e.g., difficulties with focusing, concentration, and/or remembering new information), and emotional lability (e.g., increased irritability or anxiety), as well as sleep disturbance. Symptoms typically resolve within weeks to months. ${ }^{3}$

In a previous systematic review of outcomes following mild TBI, Satz and colleagues found no immediate or longterm effects on academic or psychosocial functioning. ${ }^{33}$ Babikian and Asarnow conducted a meta-analytic review that revealed no statistically significant effects on overall neurocognitive functioning ${ }^{34}$; nevertheless, some adverse effects have been reported, including increased behavioral and learning difficulties up to 24 months postinjury. ${ }^{31,35,36}$ Most recently, Lloyd and colleagues found $6.8 \%$ of reviewed studies indicated adverse academic outcomes, $17.8 \%$ of reviewed studies indicated adverse neuropsychological outcomes, and $48.9 \%$ of reviewed studies indicated adverse psychosocial outcomes following mild TBI. ${ }^{3}$ Risk factors for protracted recovery may include previous history of repeated head injuries, headaches, attention difficulties, learning problems, or psychiatric concerns. ${ }^{37}$

\section{Moderate to Severe Traumatic Brain Injury}

Early cognitive deficits following moderate-to-severe TBI may range from severe and diffuse impairments (e.g., MCS and/or minimal responsiveness to environmental stimuli) to subtle, higher level concerns including impulsivity and/or poor safety awareness. ${ }^{38}$ Children and adolescents presenting with a moderate-to-severe TBI are more likely to present with altered consciousness (coma, unresponsive wakefulness, MCS), fluctuations in arousal, disorientation, and/or confusion. As children and adolescents become more awake and alert, previously acquired knowledge, overlearned information, and automatized skills tend to be less affected. More difficulties are observed with speeded, novel, and/or integrative tasks that require new learning. Previous studies have demonstrated poor functioning 6 months postinjury on everyday ratings of executive function, showing greater difficulties associated with severe $\mathrm{TBI}^{39}$ The fastest rate of recovery following a moderate-to-severe TBI ranges from 6 months to 2 years following injury. ${ }^{40}$

Younger age at the time of injury (less than 5 years of age) increases the risk for experiencing difficulty in acquiring broad academic skills in school. Children and adolescents who sustain moderate-to-severe TBI are also at increased risk for needing special education services, academic performance problems, and failing grades. ${ }^{41}$ In their systematic review of studies, Lloyd and colleagues found that $18.2 \%$ of reviewed studies indicated adverse academic outcomes, $31.8 \%$ of reviewed studies indicated adverse psychosocial outcomes, and $45 \%$ of reviewed studies indicated adverse neuropsychological outcomes following moderate TBI. ${ }^{3}$

Following TBI, children and adolescents may display a high incidence of behavioral disturbance, depression, and/or anxiety. Children with severe TBI have been shown to have greater overall behavioral problems 6 months postinjury compared with individuals with less severe injuries. ${ }^{39}$ Additionally, severe TBI is associated with the emergence of new undesirable behaviors, such as aggression, impulsivity, personality change, and social difficulties. ${ }^{23,42}$ Problems with social functioning have also been described after pediatric TBI. Previous research has found that children with severe TBI are rated as less socially competent, poorer social problemsolvers, and lonelier compared with healthy peers. ${ }^{24,43}$

Social difficulties may be exacerbated by poor family functioning, lower socioeconomic status, and limited resources, as well as deficits in social information-processing and social problem-solving. ${ }^{24,44-47}$ Caregiver and family burden may also emerge, especially among individuals with severe TBI. ${ }^{48,49}$ Caregivers are more likely to report family burden when their child's functioning is poorer and health care needs are unmet. ${ }^{50}$

\section{Health-Related Quality of Life}

With the advances in treatment techniques and improved survival rates, the likelihood of long-term consequences and residual deficits in children with a history of TBI is greater and may negatively impact quality of life over time. HRQL is a multidimensional construct referring to the impact of a disease or injury on patients' physical, emotional, and social wellbeing. ${ }^{51,52}$ HRQL may be a more salient outcome measure in 
pediatric TBI given previous findings that severity and allocation of services following TBI do not account for variability in social adjustment and cognitive functioning. 53

Previous studies addressing HRQL in pediatric TBI have considered the effects of injury severity; however, there is evidence to suggest recovery may occur at different rates for different HRQL domains. ${ }^{54}$ Rivara and colleagues found that children with moderate-to-severe TBI showed reduced HRQL up to 24 months postinjury, whereas children with mild TBI were not affected. ${ }^{55}$ Studies that have followed children for longer time periods have found reduced HRQL for children with TBI across severities at 1 to 5 years postinjury compared with healthy control groups. ${ }^{56} \mathrm{~A}$ recent study by Brown and colleagues found that different dimensions of HRQL were affected differentially over time. ${ }^{54}$ Children with moderate-to-severe TBI experienced greater initial dysfunction than children with mild TBI; however, this difference disappeared by 18 months following injury. Overall, research suggests that injury severity impacts overall HRQL; however, the impact on various domains may vary considering the focus of TBI recovery changes from the physical to psychosocial and family functioning over time.

Another important consideration is the method in which HRQL is measured in pediatric TBI. Currently, both parent and child reports of HRQL are used; however, they often can be discrepant. Studies have shown that, while both parents and children reported reduced HRQL following injury, parents appeared to report more difficulties compared with their children. ${ }^{57,58}$ Specifically, parents rated their child or adolescent HRQL less favorably than the children or adolescents themselves. These findings may suggest that children and adolescents may be more prone to minimizing concerns about their own health and functioning and thus report higher HRQL compared with their parents. Alternatively, it could be that the cognitive and behavioral sequelae of TBI render children and adolescents less capable of providing insight into their social and emotional functioning.

\section{Case Vignette: “Henry”}

\section{Background}

Henry, a right-handed, Caucasian adolescent, sustained a severe TBI when he was almost 16 years old when he was involved in a dirt bike accident. Prior to his trauma, Henry's birth, developmental, and educational histories were largely unremarkable. Henry was a 10th grade student at a public high school who participated in the general education curriculum. He was described as a high-achieving, "straight A" student who was motivated to perform well. Henry was enrolled in accelerated courses and managed the demands of his course load independently. Henry's parents acknowledged that Henry had experienced the deaths of two close friends $\sim 1.5$ years prior to his accident. As such, he participated in group therapy services to facilitate his grieving process. In general, Henry was described as a likable, friendly, and funny teenager who was well liked by his peers. Henry's medical history was unremarkable, except for occasional migraine headaches.

In short, Henry was an otherwise healthy teenager until he sustained a TBI. He was riding his dirt bike on a wooded trail with a friend when he crashed. He was wearing a helmet and was found unconscious at the scene. His initial GCS score was a 6 . He was intubated at the scene and transported to the hospital. Initial conventional neuroimaging (head CT) revealed no sign of intracranial injury or hemorrhage, but a subsequent MRI revealed a left subdural hemorrhage, left temporal lobe cortical contusions, and multiple shear injuries. Once medically stable, Henry was transferred to the inpatient rehabilitation unit for ongoing medical management and intensive therapies, including speech, occupational therapy, and physical therapy services (length of stay [LOS] $=6$ days). During his inpatient admission, Henry displayed notable difficulties with higher level executive dysfunction (e.g., problem-solving, planning/organization, initiation), verbal memory, and deficit/safety awareness. Upon his discharge from the hospital, Henry transitioned to the Day Rehabilitation Program for intensive outpatient neurorehabilitation (LOS $=15$ days).

\section{Neuropsychological Evaluation 1 Month after Traumatic Brain Injury}

Henry functioned in the average to high-average range. Specific areas of weakness included verbal memory, higher level executive functioning, visual-motor integration skills, and fine motor speed. Parent ratings did not endorse any clinically significant concerns with executive or behavioralemotional functioning in the everyday environment. The recommendation was made for Henry to return to school with a 504 Intervention Plan and accommodations to address his current areas of weakness.

\section{Neuropsychological Evaluation 1 Year after Traumatic Brain Injury}

From a medical standpoint, Henry remained stable; however, he and his parents reported frequent headaches, which were typically managed with over-the-counter medication. Given the persistence of his headaches, despite pharmacologic intervention, his parents explored additional treatment options. As per the suggestion of a family member, Henry had recently undergone hyperbaric oxygen therapy (HBOT) in the weeks prior to the evaluation, with qualitative improvements noted. Of note, previous research has been inadequate to support or refute the use of HBOT for migraine prevention. ${ }^{59}$ Henry also endorsed ongoing problems with sleep as well as increased concerns with stress and mood. Henry gradually returned to the school environment following his discharge from the Day Rehabilitation Program. A 504 Intervention Plan was established, which outlined specific supports and accommodations, including extended time, taking tests in a smaller group setting, and reduced homework. Henry maintained a full course load, although he was required to make up classwork from the 6 weeks that he was absent due to his hospitalization; as such, he withdrew from his honors courses. On follow-up, Henry's parents indicated that his 504 Intervention Plan was not consistently followed and implemented by teachers. Henry continued to work hard at his studies and earn straight As. Despite his high level of academic achievement, Henry and his parents acknowledged 
that it takes "much more time and effort" for him to complete his work as well as maintain his grades compared with before his injury. Due to the stress of his current course load, teachers eventually agreed to limit the amount of time spent on homework to 30 minutes each night. Henry and his parents reported more notable concerns with his mood (anxiety, depression) following his return to school. Henry was reported to have high expectations for himself and work until he "reaches his limit." He worried about pushing himself too hard and prolonging his recovery due to his involvement in extracurricular activities. Henry also thought that he was "terrible at everything" and displayed decreased enjoyment in previously preferred activities. While he had not withdrawn from social interactions, parents observed that it requires "much more energy" than before his TBI. Henry was recently prescribed Prozac by a psychiatrist to assist with mood management. Henry continues to participate in individual therapy on an as-needed basis.

Results of the updated evaluation revealed a largely stable to improved neurocognitive profile compared to his previous assessment. Specific areas of weakness included processing efficiency, higher-level executive dysfunction, and aspects of memory. While Henry continued to demonstrate nice improvements in his cognitive and physical recovery, he and his family were endorsing more significant concerns with his mood and emotional functioning in addition to frequent headaches and ongoing sleep disturbance, which appeared to be negatively impacting his quality of life. The recommendation was made to increase the level of individualized support he received at school, to prioritize psychological intervention to include regularly scheduled weekly sessions, and to receive ongoing medication management with his psychiatrist.

\section{Conclusion}

The neuropsychological, psychosocial, and academic outcomes following child and adolescent TBIs vary by a multitude of factors. Like many, including Henry, outcomes depend on various factors, including injury severity, noninjury factors, and developmental history. Furthermore, although many cognitive and physical difficulties may resolve in the years following a TBI, emotional and behavioral functioning in addition to mood and somatic concerns may become exacerbated over time, which can negatively impact the quality of life of the child. During the initial months following a severe TBI, it is important to participate in intensive rehabilitation therapies, if indicated, and obtain appropriate supports in the academic and community settings to facilitate ongoing recovery. A patient's level of functioning should be reassessed over time since the needs may differ based on their initial constellation of difficulties and stage of recovery. The case of Henry is a good example of how recovery following pediatric TBI is multifaceted. Children and adolescents may often display positive cognitive and physical recovery following a severe TBI while also experiencing persistent and lingering difficulties, which may negatively impact HRQL for both the patient and family.

\section{References}

1 Centers for Disease Control and Prevention. Report to Congress on Traumatic Brain Injury in the United States: Epidemiology and Rehabilitation. Atlanta, GA: National Center for Injury Prevention and Control; Division of Unintentional Injury Prevention; 2010

2 Bazarian JJ, McClung J, Shah MN, Cheng YT, Flesher W, Kraus J. Mild traumatic brain injury in the United States, 1998-2000. Brain Inj 2005;19(2):85-91

3 Lloyd J, Wilson ML, Tenovuo O, Saarijärvi S. Outcomes from mild and moderate traumatic brain injuries among children and adolescents: a systematic review of studies from 2008-2013. Brain Inj 2015;29(5):539-549

4 Giza CC, Mink RB, Madikians A. Pediatric traumatic brain injury: not just little adults. Curr Opin Crit Care 2007;13(2):143-152

5 Laskowitz D, Grant G. Translational Research in Traumatic Brain Injury. Boca Raton, FL: CRC Press; 2016

6 Yeates KO. Traumatic brain injury. In: Yeates KO, Ris M, Taylor H, Pennington B, eds. Neuropsychology Research, Theory, and Practice. New York, NY: Guilford Press; 2010:112-146

7 Orrison WW, Gentry LR, Stimac GK, Tarrel RM, Espinosa MC, Cobb LC. Blinded comparison of cranial CT and MR in closed head injury evaluation. AJNR Am J Neuroradiol 1994;15(2):351-356

8 Bigler ED. Anterior and middle cranial fossa in traumatic brain injury: relevant neuroanatomy and neuropathology in the study of neuropsychological outcome. Neuropsychology 2007;21(5): 515-531

9 Blackman JA, Rice SA, Matsumoto JA, et al. Brain imaging as a predictor of early functional outcome following traumatic brain injury in children, adolescents, and young adults. J Head Trauma Rehabil 2003;18(6):493-503

10 Teasdale G, Jennett B. Assessment of coma and impaired consciousness. A practical scale. Lancet 1974;2(7872):81-84

11 Suskauer SJ, Huisman TAGM. Neuroimaging in pediatric traumatic brain injury: current and future predictors of functional outcome. Dev Disabil Res Rev 2009;15(2):117-123

12 Ashwal S, Holshouser BA, Tong KA. Use of advanced neuroimaging techniques in the evaluation of pediatric traumatic brain injury. Dev Neurosci 2006;28(4-5):309-326

13 Martin C, Falcone RA Jr. Pediatric traumatic brain injury: an update of research to understand and improve outcomes. Curr Opin Pediatr 2008;20(3):294-299

14 Catroppa C, Anderson VA, Morse SA, Haritou F, Rosenfeld JV. Outcome and predictors of functional recovery 5 years following pediatric traumatic brain injury (TBI). J Pediatr Psychol 2008; 33(7):707-718

15 Stevens CP, Raz S, Sander CJ. Peripartum hypoxic risk and cognitive outcome: a study of term and preterm birth children at early school age. Neuropsychology 1999;13(4):598-608

16 Anderson V, Catroppa C, Morse S, Haritou F, Rosenfeld JV. Intellectual outcome from preschool traumatic brain injury: a 5-year prospective, longitudinal study. Pediatrics 2009;124(6): e1064-e1071

17 Taylor HG, Yeates K, Wade S, Drotar D, Stancin T, Montpetite M. Long-term educational interventions after traumatic brain injury in children. Rehabil Psychol 2003;48(4):227-236

18 Glang A, Todis B, Thomas CW, Hood D, Bedell G, Cockrell J. Return to school following childhood TBI: who gets services? NeuroRehabilitation 2008;23(6):477-486

19 Brown G, Chadwick O, Shaffer D, Rutter M, Traub M. A prospective study of children with head injuries: III. Psychiatric sequelae. Psychol Med 1981;11(1):63-78

20 Wechsler B, Kim H, Gallagher PR, DiScala C, Stineman MG. Functional status after childhood traumatic brain injury. J Trauma 2005;58(5):940-949, discussion 950

21 Schwartz L, Taylor HG, Drotar D, Yeates KO, Wade SL, Stancin T. Long-term behavior problems following pediatric traumatic brain 
injury: prevalence, predictors, and correlates. J Pediatr Psychol 2003;28(4):251-263

22 Yeates KO, Taylor HG, Drotar D, et al. Preinjury family environment as a determinant of recovery from traumatic brain injuries in school-age children. J Int Neuropsychol Soc 1997;3(6):617-630

23 Taylor HG, Yeates KO, Wade SL, Drotar D, Stancin T, Minich N. A prospective study of short- and long-term outcomes after traumatic brain injury in children: behavior and achievement. Neuropsychology 2002;16(1):15-27

24 Yeates KO, Swift E, Taylor HG, et al. Short- and long-term social outcomes following pediatric traumatic brain injury. J Int Neuropsychol Soc 2004;10(3):412-426

25 Anderson VA, Catroppa C, Haritou F, Morse S, Rosenfeld JV. Identifying factors contributing to child and family outcome 30 months after traumatic brain injury in children. J Neurol Neurosurg Psychiatry 2005;76(3):401-408

26 Anderson V, Moore C. Age at injury as a predictor of outcome following pediatric head injury: a longitudinal perspective. Child Neuropsychol 1995;1:187-202

27 Taylor HG, Alden J. Age-related differences in outcomes following childhood brain insults: an introduction and overview. J Int Neuropsychol Soc 1997;3(6):555-567

28 Anderson V, Jacobs R, Spencer-Smith M, et al. Does early age at brain insult predict worse outcome? Neuropsychological implications. J Pediatr Psychol 2010;35(7):716-727

29 Donders J. Traumatic brain injury. In: Hunter SJ, Donders J, eds. Pediatric Neuropsychological Intervention. New York, NY: Cambridge University Press; 2007:91-111

30 Ylvisaker M, Feeney T. Pediatric brain injury: social, behavioral, and communication disability. Phys Med Rehabil Clin N Am 2007; 18(1):133-144, vii

31 McKinlay A, Grace R, Horwood J, Fergusson D, MacFarlane M. Adolescent psychiatric symptoms following preschool childhood mild traumatic brain injury: evidence from a birth cohort. J Head Trauma Rehabil 2009;24(3):221-227

32 Crowe LM, Catroppa C, Babl FE, Rosenfeld JV, Anderson V. Timing of traumatic brain injury in childhood and intellectual outcome. J Pediatr Psychol 2012;37(7):745-754

33 Satz P, Zaucha K, McCleary C, Light R, Asarnow R, Becker D. Mild head injury in children and adolescents: a review of studies (19701995). Psychol Bull 1997;122(2):107-131

34 Babikian T, Asarnow R. Neurocognitive outcomes and recovery after pediatric TBI: meta-analytic review of the literature. Neuropsychology 2009;23(3):283-296

35 Hanten G, Li X, Newsome M, et al. Oral reading and expressive language after childhood traumatic brain injury: trajectory and correlates of changes over time: prospective study. Top Lang Disord 2009;29:238-244

36 Hanten G, Li X, Newsome M, et al. Oral reading and expressive language after childhood traumatic brain injury: trajectory and correlates of changes over time: retrospective study. Top Lang Disord 2009;29:244-248

37 Kirkwood MW, Yeates KO, Taylor HG, Randolph C, McCrea M, Anderson VA. Management of pediatric mild traumatic brain injury: a neuropsychological review from injury through recovery. Clin Neuropsychol 2008;22(5):769-800

38 Jaffe KM, Fay GC, Polissar NL, et al. Severity of pediatric traumatic brain injury and early neurobehavioral outcome: a cohort study. Arch Phys Med Rehabil 1992;73(6):540-547

39 Anderson V, Le Brocque R, Iselin G, et al. Adaptive ability, behavior and quality of life pre and posttraumatic brain injury in childhood. Disabil Rehabil 2012;34(19):1639-1647

40 Fay TB, Yeates KO, Wade SL, Drotar D, Stancin T, Taylor HG. Predicting longitudinal patterns of functional deficits in children with traumatic brain injury. Neuropsychology 2009;23(3):271-282

41 Kinsella GJ, Prior M, Sawyer M, et al. Predictors and indicators of academic outcome in children 2 years following traumatic brain injury. J Int Neuropsychol Soc 1997;3(6):608-616
42 Fletcher JM, Ewing-Cobbs L, Miner ME, Levin HS, Eisenberg HM. Behavioral changes after closed head injury in children. J Consult Clin Psychol 1990;58(1):93-98

43 Dennis M, Guger S, Roncadin C, Barnes M, Schachar R. Attentionalinhibitory control and social-behavioral regulation after childhood closed head injury: do biological, developmental, and recovery variables predict outcome? J Int Neuropsychol Soc 2001;7(6): 683-692

44 Dennis M, Barnes MA, Wilkinson M, Humphreys RP. How children with head injury represent real and deceptive emotion in short narratives. Brain Lang 1998;61(3):450-483

45 Dennis M, Purvis K, Barnes MA, Wilkinson M, Winner E. Understanding of literal truth, ironic criticism, and deceptive praise following childhood head injury. Brain Lang 2001;78(1):1-16

46 Hanten G, Wilde EA, Menefee DS, et al. Correlates of social problem solving during the first year after traumatic brain injury in children. Neuropsychology 2008;22(3):357-370

47 Janusz JA, Kirkwood MW, Yeates KO, Taylor HG. Social problemsolving skills in children with traumatic brain injury: long-term outcomes and prediction of social competence. Child Neuropsychol 2002;8(3):179-194

48 Osberg JS, Brooke MM, Baryza MJ, Rowe K, Lash M, Kahn P. Impact of childhood brain injury on work and family finances. Brain Inj 1997;11(1):11-24

49 Hawley CA, Ward AB, Magnay AR, Long J. Parental stress and burden following traumatic brain injury amongst children and adolescents. Brain Inj 2003;17(1):1-23

50 Aitken ME, McCarthy ML, Slomine BS, et al; CHAT Study Group. Family burden after traumatic brain injury in children. Pediatrics 2009;123(1):199-206

51 Varni JW, Seid M, Kurtin PS. PedsQL 4.0: reliability and validity of the Pediatric Quality of Life Inventory version 4.0 generic core scales in healthy and patient populations. Med Care 2001;39(8): 800-812

52 WHOQOL Group. The World Health Organization Quality of Life Assessment (WHOQOL): development and general psychometric properties. Soc Sci Med 1998;46(12):1569-1585

53 Wells R, Minnes P, Phillips M. Predicting social and functional outcomes for individuals sustaining paediatric traumatic brain injury. Dev Neurorehabil 2009;12(1):12-23

54 Brown EA, Kenardy J, Chandler B, Anderson V, McKinlay L, Le Brocque R. Parent-reported health related quality of life in children with traumatic brain injury: a prospective study. J Pediatr Psychol 2016;41(2):244-255

55 Rivara FP, Koepsell TD, Wang J, et al. Disability 3, 12, and 24 months after traumatic brain injury among children and adolescents. Pediatrics 2011;128(5):e1129-e1138

56 Limond J, Dorris L, McMillan TM. Quality of life in children with acquired brain injury: parent perspectives $1-5$ years after injury. Brain Inj 2009;23(7):617-622

57 Erickson SJ, Montague EQ Gerstle MA. Health-related quality of life in children with moderate-to-severe traumatic brain injury. Dev Neurorehabil 2010;13(3):175-181

58 Yeates KO, Taylor HG, Wade SL, Drotar D, Stancin T, Minich N. A prospective study of short- and long-term neuropsychological outcomes after traumatic brain injury in children. Neuropsychology 2002;16:514-523

59 Holland S, Silberstein SD, Freitag F, Dodick DW, Argoff C, Ashman E; Quality Standards Subcommittee of the American Academy of Neurology and the American Headache Society. Evidence-based guideline update: NSAIDs and other complementary treatments for episodic migraine prevention in adults: report of the Quality Standards Subcommittee of the American Academy of Neurology and the American Headache Society. Neurology 2012;78(17): 1346-1353

60 Management of Concussion/mTBI Working Group. VA/DoD clinical practice guideline for management of concussion/mild traumatic brain injury. J Rehabil Res Dev 2009;46(6):CP1-CP68 